\title{
A Preliminary Report on Herbal Medicine Use Among Patients Hospitalized at Two-Large COVID-19 Treatment Centers in Uganda
}

\author{
Phillip Musoke $\mathbb{D}^{1}$ \\ Jerom Okot (iD ${ }^{2}$ \\ Vivien Nanfuka ${ }^{3}$ \\ Pius Rwamafa ${ }^{4}$ \\ Joseph Masajjage ${ }^{3}$ \\ Ivan Kisuule ${ }^{4}$ \\ Brandy Nantaayi (iD) \\ Nelson Ssewante ${ }^{\prime}{ }^{\prime}$ \\ Felix Bongomin (D) ${ }^{1,2}$ \\ 'School of Medicine, College of Health \\ Sciences, Makerere University, Kampala, \\ Uganda; ${ }^{2}$ Department of Medical \\ Microbiology and Immunology, Faculty of \\ Medicine, Gulu University, Gulu, Uganda; \\ ${ }^{3}$ Department of Internal Medicine, \\ Kiruddu National Referral Hospital, \\ Kampala, Uganda; ${ }^{4}$ Department of \\ Internal Medicine, Mulago National \\ Referral Hospital, Kampala, Uganda
}

Correspondence: Felix Bongomin Department of Medical Microbiology and Immunology, Faculty of Medicine, Gulu University, P. O. Box, 166, Gulu, Uganda Email drbongomin@gmail.com
Introduction: Herbal medication use among patients with COVID-19 imposes a significant risk of drug-herbal interactions and adverse events. This study aimed to assess the prevalence and factors associated with herbal medicine use among patients hospitalized with COVID-19 attending two large COVID-19 Treatment Units (CTU) in Uganda.

Methods: A hospital-based descriptive cross-sectional study was conducted recruiting patients with COVID-19 hospitalized at the Mulago National Referral Hospital and Namboole Stadium CTUs. Chi-square or Fishers' exact test for categorical and Mann-Whitney $U$-test for numerical were used to determine the association between dependent and independent variables.

Results: The study was terminated early because of significant reduction in the number of patients hospitalized with COVID-19 and the closure of Namboole CTU. Of the anticipated 422 participants, we recruited $108(25.6 \%)$. Of this, $58(53.7 \%)$ were female, with a median age of 38 (range: $20-75)$ years. Forty-nine (45.4\%) had received at least one dose of the COVID-19 vaccine. Fifty-eight $(57.3 \%)$ of the participants had ever used herbal medicine and the majority had used them in the past 12 months $(71.9 \%, \mathrm{n}=41)$ either before the diagnosis of COVID-19 $(85.4 \%, \mathrm{n}=35)$ or after $(36.6 \%, \mathrm{n}=15)$. Being vaccinated for COVID-19 (adjusted odds ratio (aOR): 3.1, 95\% confidence interval (CI): $1.4-6.8, \mathrm{p}=$ 0.005 ) and having attained tertiary level of education (aOR: 6.2, 95\% CI: 1.7-23.1, p = 0.006), as well as the accessibility to herbalists (aOR: 31.2, 95\% CI: 3.7-263.2, p = 0.002) were significantly associated with herbal medication use. The majority of participants reported some improvement after using herbal medicine $(80.7 \%, \mathrm{n}=46)$ and their doctors or nurses asked almost half of the participants about herbal medicine use $(49.5 \%, \mathrm{n}=53)$. Conclusion: The use of herbal medicines to treat or prevent COVID-19 among hospitalized patients is a widespread practice in Uganda amidst unpublished evidence of their safety and efficacy.

Keywords: COVID-19, prevalence, herbal medicine use, Uganda

\section{Introduction}

Globally, herbal medicines use has been reported as a common practice both in the prevention and treatment of diseases. ${ }^{1-3}$ This is especially common with diseases with high mortality, morbidity or those without conventional therapy that cure the disease. Previous studies in Uganda report that more than $60 \%$ of the population depended on traditional medicine before the coronavirus disease (COVID-19) pandemic. 4 Due to the high mortality associated with the second wave of COVID-19, this practice is likely to have increased. 
Many factors have been identified as drivers of herbal medicine use. In many parts of the world, users have reported that herbal remedies are safe, effective, and are cheap. ${ }^{1,5}$ In Uganda, easy access, and cultural familiarity as well as the higher number of traditional health practitioners compared to health-care professionals are some of the common factors influencing this practice. ${ }^{4,6} \mathrm{~A}$ recent study in Uganda reported that media has increased the use of herbal medicines in the treatment and prevention of COVID-19. ${ }^{7}$ However, there is limited information concerning the level of herbal medicine use among hospitalized COVID-19 patients and the reasons why they resort to this practice even with the existence of conventional supportive treatment and vaccines.

Although some studies have reported the role of combining herbal remedies with westernized medicine in the treatment of COVID- $19,{ }^{8}$ the side effects of these remedies are not well studied. This is in addition to the wide variation in the types of herbal medicines on the market which may wrongly influence their use. Various studies have documented harmful consequences of herbal remedies including hepatotoxicity and allergies, which may be worsened by confounders such as self-medication. ${ }^{1,9}$ The continued use of herbal medicines without question may lead to long-term health consequences for both the individual and the government.

The Uganda National Drug Policy and Authority Statute (1993) gives the National Drug Authority (NDA) a mandate to regulate herbal medicine use including approving of all manufacturers. During the pandemic, several manufacturers have hit the market with herbal medicine products, but only a few of these are approved by the NDA and little has been done to regulate their practice. ${ }^{10}$ This study, therefore, aimed to determine the prevalence of and factors associated with herbal medicine use among hospitalized patients at the two large COVID19 treatment units in Uganda.

\section{Methods}

\section{Study Design and Setting}

An observational, cross-sectional study was conducted between July and August 2021 in two large CTUs in Kampala, Uganda, namely, Mulago National Referral Hospital CTU and Namboole Stadium CTU. These are the main referral CTUs in the country with bed capacities of over 30,000 beds catering for a diverse range of patients from all over the country. The CTUs run daily, seeing both patients referred from other health facilities across the country as well as patients who are being followed up routinely.

\section{Study Population}

We approached all patients hospitalized with COVID-19 in the two-largest CTUs in the country. Eligible participants

Table I Socio-Demographic Characteristics of Participants

\begin{tabular}{|c|c|c|}
\hline Variable & Frequency & Percentage \\
\hline Median age (interquartile range) & 38 & $20-75$ \\
\hline$<39$ years & 58 & 53.7 \\
\hline$\geq 39$ years & 50 & 46.3 \\
\hline \multicolumn{3}{|l|}{ Sex } \\
\hline Female & 62 & 57.4 \\
\hline Male & 46 & 42.6 \\
\hline \multicolumn{3}{|l|}{ Region of residence } \\
\hline Central & 76 & 70.4 \\
\hline East & 11 & 10.2 \\
\hline North & 3 & 2.8 \\
\hline West & 18 & 16.7 \\
\hline \multicolumn{3}{|l|}{ Level of education $(n=106)$} \\
\hline Primary & 19 & 17.8 \\
\hline Secondary & 31 & 29.3 \\
\hline Tertiary & 40 & 37.7 \\
\hline None & 16 & 15.1 \\
\hline \multicolumn{3}{|l|}{ Formal employment status } \\
\hline Employed & 61 & 56.5 \\
\hline Not employed & 47 & 43.5 \\
\hline \multicolumn{3}{|l|}{ Religion } \\
\hline Christianity & 72 & 66.7 \\
\hline Islam & 17 & 15.7 \\
\hline Others & 19 & 17.6 \\
\hline \multicolumn{3}{|l|}{ Marital status } \\
\hline Married & 57 & 52.8 \\
\hline Divorced & 10 & 9.3 \\
\hline Single & 32 & 29.6 \\
\hline Window/widower & 9 & 8.3 \\
\hline \multicolumn{3}{|l|}{ Treatment site } \\
\hline Mulago & 45 & 41.7 \\
\hline Namboole & 63 & 58.3 \\
\hline \multicolumn{3}{|l|}{ Vaccination status } \\
\hline Vaccinated & 49 & 45.4 \\
\hline Not vaccinated & 59 & 54.6 \\
\hline \multicolumn{3}{|l|}{ On treatment for COVID-19 } \\
\hline No & 14 & 13.1 \\
\hline Yes & 93 & 86.9 \\
\hline
\end{tabular}

Abbreviation: n, number of participants. 


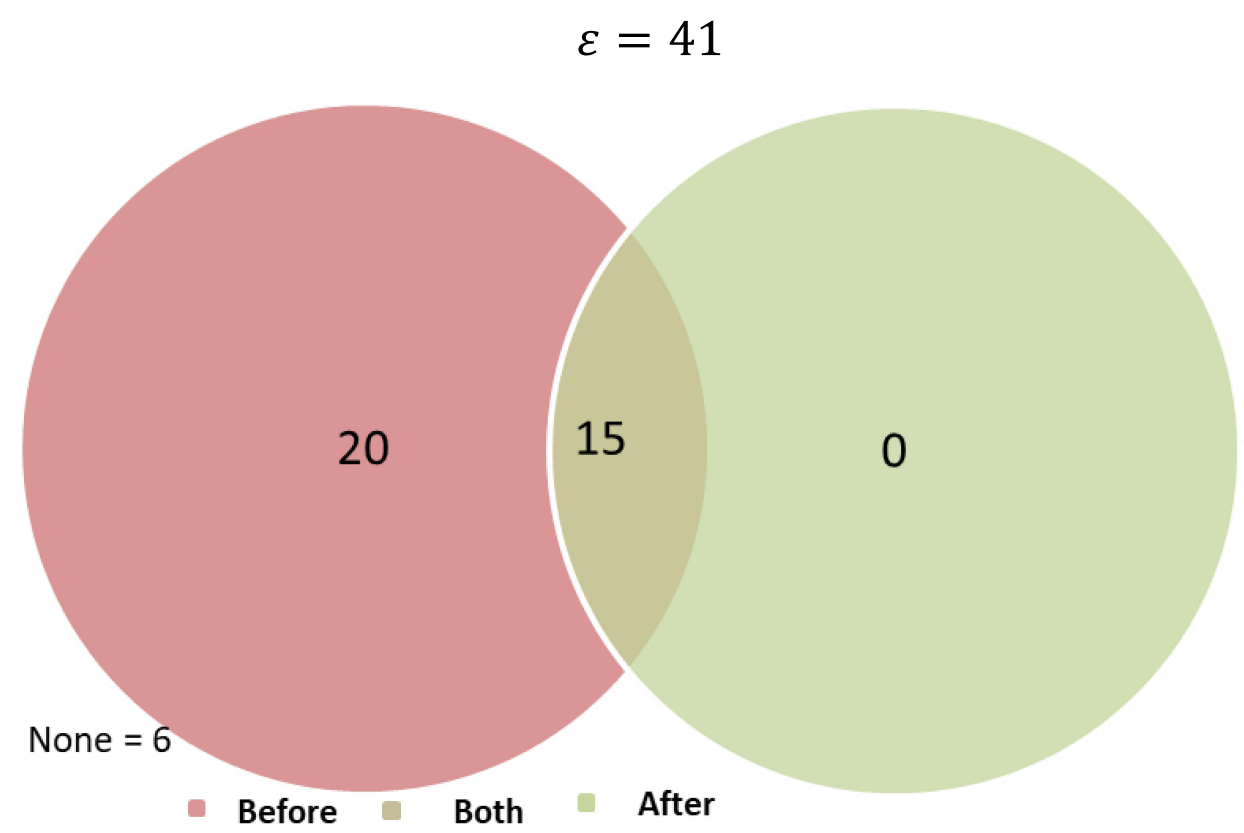

Figure I Herbal medical use before and after diagnosis of COVID-19 in the last 12 months. $\varepsilon$ represents the total number of patients who had used herbal medicines in the last 12 months before this survey.

were those confirmed to have COVID-19 and aged 18 years and above. Respondents with a known history of impaired mental capacity to provide coherent and reliable information, critically ill in the absence of a reliable caretaker were excluded.

\section{Sample Size Calculation}

The sample size was calculated using the Kish Leslie formula for cross-sectional studies where the estimated sample size at $95 \%$ confidence interval was 384 participants. To cater for non-response associated with critically ill, unable to provide information or absence of caretakers, $10 \%$ of the estimated sample size was added leading to a final sample size of 422 participants.

\section{Questionnaire Development}

The questionnaire was divided into three major sections: socio-demographic characteristics (age, gender, tribe, religion, education level, employment status, occupation, residence), herbal medicine use assessment (prevalence, and reasons for herbal medicine use), and factors associated with herbal medicine use with both open and closed-ended questions.

\section{Measurements}

The questions asked were modified from the International Questionnaire to Measure Use of Complementary and
Alternative Medicine (I-CAM-Q); which aims to comparably assess the use of CAM internationally. ${ }^{11}$

\section{Data Analysis and Management}

Fully completed questionnaires were extracted from KoBo Toolbox $^{\circledR}$ and exported to a Microsoft Excel 2016 for cleaning and coding. The cleaned data was exported to STATA 16 (StataCorp LLC, College Station, Texas, USA) for analysis. Numerical data were then summarized as means and standard deviations or median and range as appropriate. Categorical variables were summarized as frequencies and relative percentages. To assess the association between independent variables with herbal medicine use, chi-square test or Fishers' exact test (for categorical variables) and Mann-Whitney $U$-test (for continuous variables) were used at bivariate analysis. All independent variables with $\mathrm{p}<0.2$ at bivariate analysis were included in the multivariable logistic regression models to adjust for confounders. A $\mathrm{p}<0.05$ was considered statistically significant.

\section{Ethics}

The study was performed according to the Declaration of Helsinki, after obtaining approval from Mulago Hospital Research and Ethics Committee (Approval number MHREC 2097). Consent forms were given to respondents before the initiation of the study. 
Table 2 Herbal Medicine Use Among the Participants

\begin{tabular}{|c|c|c|}
\hline Variable & Frequency & Percentage \\
\hline \multicolumn{3}{|c|}{ Have you ever used herbal medicine } \\
\hline Yes & 58 & 53.7 \\
\hline No & 50 & 46.3 \\
\hline \multicolumn{3}{|c|}{ Ever used herbal medicine in the last 12 months $(n=57)$} \\
\hline No & 16 & 28.1 \\
\hline Yes & 41 & 71.9 \\
\hline \multicolumn{3}{|c|}{ Current use of herbal medicine $(n=57)$} \\
\hline No & 30 & 52.6 \\
\hline Yes & 27 & 47.4 \\
\hline \multicolumn{3}{|c|}{ Using COVIDEX to treat current symptoms } \\
\hline No & 79 & 73.8 \\
\hline Yes & 28 & 26.2 \\
\hline \multicolumn{3}{|c|}{$\begin{array}{l}\text { Accessibility of herbal medicine as compared to } \\
\text { conventional }\end{array}$} \\
\hline $\begin{array}{l}\text { Health care provider more } \\
\text { accessible }\end{array}$ & 42 & 39 \\
\hline Herbalists are more accessible & 15 & 13.9 \\
\hline They are equality accessible & 51 & 47.2 \\
\hline \multicolumn{3}{|c|}{ Any improvement after using herbal medicine $(n=57)$} \\
\hline No & 11 & 19.3 \\
\hline Yes & 46 & 80.7 \\
\hline \multicolumn{3}{|c|}{ Doctor/nurse asked about herbal medical use $(n=107)$} \\
\hline No & 54 & 50.5 \\
\hline Yes & 53 & 49.5 \\
\hline
\end{tabular}

Abbreviation: $n$, number of participants.

\section{COVID 19 Precautions}

The study was conducted following the Ministry of Health and the National COVID-19 task force guidelines of Uganda.

\section{Results}

\section{Characteristics of the Participants}

The study was terminated early because of a significant reduction in the number of patients hospitalized with COVID-19 and the closure of one of the CTUs. Of the anticipated 422 participants, we recruited 108 (25.6\%). Of the 108 participants, $58(53.7 \%)$ were female, with a median age of 38 (range: 20-75) years. Majority of the participants were from central Uganda $(70.4 \%, \mathrm{n}=76)$ and were Christians $(66.7 \%, \mathrm{n}=72)$, more than one-third attained tertiary level of education $(37.7 \%, \mathrm{n}=40)$. More than half were employed $(56.5 \%, \mathrm{n}=61)$ and were married $(52.8 \%, \mathrm{n}=57)$. Forty-nine $(45.4 \%)$ participants had received at least one dose of the COVID-19 vaccine. Majority were on COVID-19 treatment (86.9\%) and more than half were getting their treatment from Namboole CTU $(58.3 \%, \mathrm{n}=53)$. Table 1 summarizes the socio-demographic characteristics of participants.

\section{Herbal Medical Use}

Of the 108 participants, 58 (57.3\%) ever used herbal medicine and the majority had used herbal medicine in the past 12 months $(71.9 \%, n=41)$. Of those that had used herbal medicines in the past 12 months, 35 (85.4\%) had used before a diagnosis of COVID-19, and 15 (36.6\%) continued to use even while on treatment for COVID-19 (Figure 1). Their doctors or nurses asked almost half of the participants about herbal medicine $(49.5 \%, \mathrm{n}=53)$, and the majority reported some improvement after using herbal medicine $(80.7 \%, \mathrm{n}=46)$. Table 2 summarizes the use of herbal medicine by the participants. Of those that were using herbal medicines, efficacy, accessibility, and affordability were the frequently reported as the reasons for their use $(\mathrm{n}=35,60.3 \%),(\mathrm{n}=14,24.1 \%)$ and $(\mathrm{n}=14,24.1 \%)$, respectively (Figure 2A). Gastrointestinal disturbances such as diarrhea, constipation, abdominal pain, and vomiting were the most commonly reported side effects associated with the use of herbal medicines (Figure 2B).

Table 3 summarizes factors associated with herbal medicine use among the participants at bivariate analysis. Vaccination status $(\mathrm{p}=0.004)$, level of education $(\mathrm{p}=$ 0.002 ), and accessibility of the herbalists vs conventional treatment $(\mathrm{p}<0.001)$. Table 4 summarizes factors associated with herbal medicine use among the participants at multivariable logistic regression: being vaccinated (adjusted odds ratio (aOR): $3.1,95 \% \mathrm{CI}: 1.4-6.8, \mathrm{p}=0.005$ ) and having attained a tertiary level of education (aOR: $6.2,95 \%$ CI: $1.7-$ $23.1, \mathrm{p}=0.006$ ), as well as the accessibility of the herbalists (aOR: 31.2, 95\% CI: 3.7-263.2, $\mathrm{p}=0.002$ ).

\section{Discussion}

In the current study, the prevalence of herbal medicine use was found to be $57.3 \%$. All participants who reported to have used herbal medicines started to use before hospital-based treatment a third of whom continued to use even after initiation of COVID-19 treatment. This finding was consistent with the results of a cross-sectional online survey among Vietnamese adults that found nearly half of the respondents 


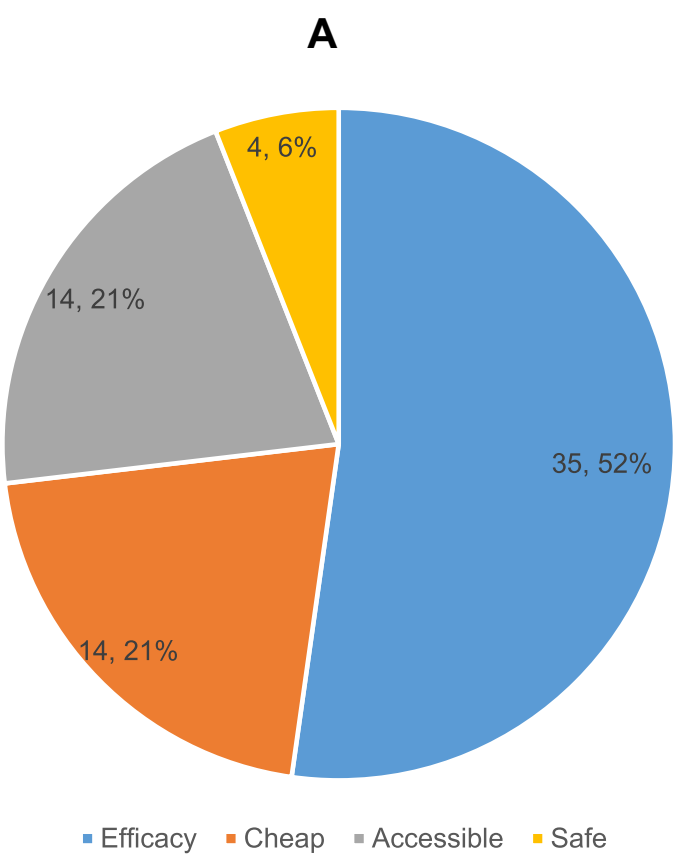

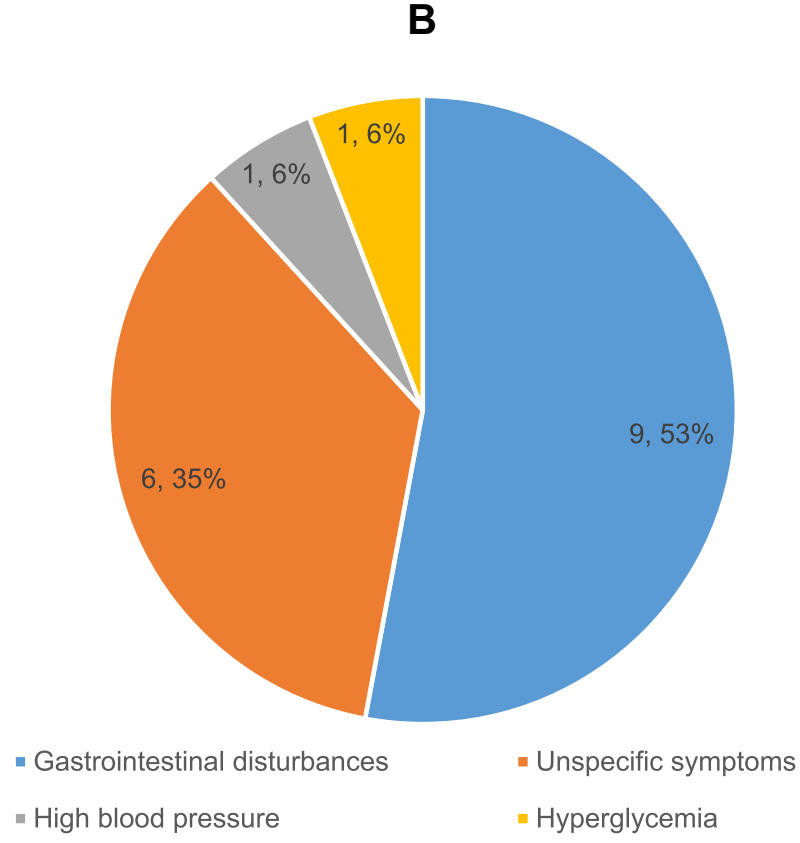

Figure 2 (A) Reasons for use of herbal medicines among COVID-19 patients. (B)

B) Common side effects of herbal medicines reported.

to use herbal medicine for common illnesses during the COVID-19 pandemic. ${ }^{12}$ However, studies from Saudi Arabia report rather a higher prevalence $(>90 \%)$ of herbal medicines use in the management of COVID-19 and other conditions. ${ }^{1,5,13}$ This big difference in the prevalence could be explained by the fact that our study assessed herbal medicine use among virologically confirmed patients, unlike the Saudi Arabian study whose participants reported to have used herbs for boosting their immunity and to improve general health and not to cure infection. ${ }^{13}$ However, a finding of herbal medicine use of more than half in our study is concerning given limited evidence supporting efficacy and safety of herbal medicines. In fact, previous studies in Uganda assessing herbal medicine use have reported a comparatively high prevalence. ${ }^{6,14,15}$ Easy access, affordability, cultural familiarity, and the unfavorable doctorpatient ratio in Uganda are the major factors leading to increased herbal medicine use. ${ }^{4}$

Being vaccinated, having attained a tertiary level of education, as well as the accessibility of the herbalists were found to be significantly associated with herbal medicines in this study. This finding corroborates with the results of a study conducted in Vietnam which reported higher levels of income, urban dwellers, and higher levels of education to be more likely to use herbal medicines in the management of COVID-19. ${ }^{12}$ Although studies from other countries have reported a predilection of females towards herbal medicine use, ${ }^{12,16}$ this was not the case in our study. Our study revealed that participants who were vaccinated against COVID-19 continued to use herbal medicine for prevention and treatment. Notably, still, our participants believed that herbal medicines were safe and effective corroborating findings reported by Nguyen et al, in which nearly $70 \%$ of participants considered herbal medicines safe and effective. ${ }^{12}$ With limited research evidencing the efficacy, mode of action, and toxicity profiles of the common herbal medicines on market, the population is at great risk of drug-herbal medicine interactions, drug resistance, and unexplained adverse reactions. Efforts should be directed towards further studies to understand the role of herbal remedies in patient management and public awareness to guide their utilization.

To the best of our knowledge, this is the first study in subSaharan Africa to assess the use of herbal medicine among COVID 19 patients hospitalized in treatment centers. Previous studies on herbal medicine use in Uganda and other subSaharan countries have focused on populations with HIV, hepatitis, and hypertension and there is a paucity of literature on the prevalence and rationale of herbal medicine use among patients with COVID-19 in sub-Saharan Africa. ${ }^{17,18}$ Findings from this study provide documented evidence on herbal medicine use among the population of COVID-19 patients, which will be used to promote public awareness, and knowledge of proper use of herbal therapies and contribute to the National 
Table 3 Bivariate Analysis for Socio-Demographic Factors Associated with Herbal Medical Use

\begin{tabular}{|c|c|c|c|c|}
\hline \multirow[t]{2}{*}{ Variable } & \multirow{2}{*}{$\begin{array}{l}\text { ALL }(n=108) \text { Freq } \\
(\%)\end{array}$} & \multicolumn{2}{|c|}{ Herbal Medical Use } & \multirow[t]{2}{*}{$\mathbf{P}$ value } \\
\hline & & $\begin{array}{l}\text { Yes }(n=58) \text { Freq } \\
(\%)\end{array}$ & $\begin{array}{l}\text { No }(n=50) \text { Freq } \\
(\%)\end{array}$ & \\
\hline Median age (interquartile range) & $38(20-75)$ & & & 0.152 \\
\hline Age range & & & & 0.250 \\
\hline$<39$ years & $58(53.7)$ & $28(48.3)$ & $30(60)$ & \\
\hline$\geq 39$ years & $50(46.3)$ & $30(51.7)$ & $20(40)$ & \\
\hline Sex & & & & 0.468 \\
\hline Female & $62(57.4)$ & $34(58.6)$ & $28(56)$ & \\
\hline Male & $46(42.6)$ & $24(41.4)$ & $22(44)$ & \\
\hline Region of residence & & & & 0.875 \\
\hline Central & $76(70.4)$ & $39(67.2)$ & $37(74)$ & \\
\hline East & II (I0.2) & $6(10.3)$ & $5(10)$ & \\
\hline North & $3(2.8)$ & $2(3.5)$ & I (2) & \\
\hline West & $18(16.7)$ & II (19) & $7(14)$ & \\
\hline Level of education $(n=106)$ & & & & 0.002 \\
\hline Primary & $19(17.8)$ & $15(26.8)$ & $4(8)$ & \\
\hline Secondary & $31(29.3)$ & $16(28.6)$ & $15(30)$ & \\
\hline Tertiary & $40(37.7)$ & $13(23.2)$ & $27(54)$ & \\
\hline None & $16(15.1)$ & $12(21.4)$ & $4(8)$ & \\
\hline Formal employment status & & & & 0.102 \\
\hline Employed & $61(56.5)$ & $29(50)$ & $32(64)$ & \\
\hline Not employed & $47(43.5)$ & $29(50)$ & $18(36)$ & \\
\hline Religion & & & & 0.777 \\
\hline Christianity & $72(66.7)$ & $37(63.8)$ & $35(70)$ & \\
\hline Islam & $17(15.7)$ & $10(17.2)$ & $7(14)$ & \\
\hline Others & $19(17.6)$ & $11(19)$ & $8(16)$ & \\
\hline Marital status & & & & 0.148 \\
\hline Married & $57(52.8)$ & $25(43.1)$ & $32(64)$ & \\
\hline Divorced & $10(9.3)$ & $6(10.3)$ & $4(8)$ & \\
\hline Single & $32(29.6)$ & $20(34.5)$ & $12(24)$ & \\
\hline Window/widower & $9(8.3)$ & $7(12.1)$ & $2(4)$ & \\
\hline Treatment site & & & & 0.301 \\
\hline Mulago & $45(4 I .7)$ & $26(44.8)$ & $19(38)$ & \\
\hline Namboole & $63(58.3)$ & $32(55.2)$ & $31(62)$ & \\
\hline Vaccination status & & & & 0.004 \\
\hline Vaccinated & $49(45.4)$ & $39(67.2)$ & $20(40)$ & \\
\hline Not vaccinated & $59(54.6)$ & $19(32.8)$ & $30(60)$ & \\
\hline On treatment for COVID-I9 & & & & 0.291 \\
\hline No & $14(13.1)$ & $6(10.5)$ & $8(16)$ & \\
\hline Yes & $93(86.9)$ & $51(89.5)$ & $42(84)$ & \\
\hline \multicolumn{5}{|c|}{$\begin{array}{l}\text { Ever used herbal medicine in the last } 12 \text { months } \\
(n=57)\end{array}$} \\
\hline No & $16(28.1)$ & $16(28.1)$ & $0(0)$ & Not \\
\hline Yes & $4 I(7 I .9)$ & $41(71.9)$ & $0(0)$ & applicable \\
\hline
\end{tabular}

(Continued) 
Table 3 (Continued).

\begin{tabular}{|c|c|c|c|c|}
\hline \multirow[t]{2}{*}{ Variable } & \multirow{2}{*}{$\begin{array}{l}\text { ALL }(n=108) \text { Freq } \\
(\%)\end{array}$} & \multicolumn{2}{|c|}{ Herbal Medical Use } & \multirow[t]{2}{*}{$P$ value } \\
\hline & & $\begin{array}{l}\text { Yes }(n=58) \text { Freq } \\
(\%)\end{array}$ & $\begin{array}{l}\text { No }(n=50) \text { Freq } \\
(\%)\end{array}$ & \\
\hline $\begin{array}{l}\text { Using COVIDEX to treat current symptoms } \\
\text { No } \\
\text { Yes }\end{array}$ & $\begin{array}{l}79(73.8) \\
28(26.2)\end{array}$ & $\begin{array}{l}33(56.9) \\
25(43.1)\end{array}$ & $\begin{array}{l}46(93.9) \\
3(6.1)\end{array}$ & $<0.001$ \\
\hline $\begin{array}{l}\text { Accessibility of herbal medicine as compared to } \\
\text { conventional } \\
\text { Health care provider more accessible } \\
\text { Herbalists are more accessible } \\
\text { They are equality accessible }\end{array}$ & $\begin{array}{l}42(39) \\
15(13.9) \\
51(47.2)\end{array}$ & $\begin{array}{l}13(22.4) \\
14(24.1) \\
31(53.5)\end{array}$ & $\begin{array}{l}29(58) \\
I(2) \\
20(40)\end{array}$ & $<0.001$ \\
\hline $\begin{array}{l}\text { Doctor/nurse asked about herbal medical use }(n=107) \\
\text { No } \\
\text { Yes }\end{array}$ & $\begin{array}{l}54(50.5) \\
53(49.5)\end{array}$ & $\begin{array}{l}28(49.1) \\
29(50.9)\end{array}$ & $\begin{array}{l}26(52) \\
24(48)\end{array}$ & 0.459 \\
\hline
\end{tabular}

Abbreviations: $n$, number of participants; \%, proportion of participants.

Drug Authority's objective to regulate the use of herbal medicine in Uganda. This information can also be used to promote activities to bring about improved communication between patients and health workers about herbal medicine use.

\section{Limitations}

Several limitations were taken into consideration as we interpreted these results. First, the study employed a non-random sample. Participation in the study was voluntary and no information was available about the characteristics of those who did not participate. Secondly, the cross-sectional design of our study does not allow for a causal interpretation of the results. Thirdly, the CTUs employed were geographically situated in town and this could have limited access to populations in rural areas who could have reflected different study findings. However, despite these limitations, this is the first study in Uganda assessing the prevalence of herbal medicine use and its associated factors among hospitalized COVID-19 patients.

\section{Conclusion}

The use of herbal medicine during the COVID-19 pandemic is a widespread practice among the general population in

Table 4 A Multivariable Logistic Regression Showing Predictors of Use of Herbal Medical Use

\begin{tabular}{|c|c|c|c|}
\hline Variable & Adjusted Odds Ratio & $95 \% \mathrm{Cl}$ & P-value \\
\hline \multicolumn{4}{|l|}{ Vaccination status } \\
\hline Vaccinated & 3.1 & $1.4-6.8$ & 0.005 \\
\hline Not vaccinated & Reference & - & \\
\hline \multicolumn{4}{|l|}{ Level of education } \\
\hline Primary & 0.8 & $0.2-3.9$ & 0.782 \\
\hline Secondary & 2.8 & $0.7-10.7$ & 0.128 \\
\hline Tertiary & 6.2 & I.7-23.I & 0.006 \\
\hline None & Reference & - & \\
\hline \multicolumn{4}{|l|}{ Accessibility of herbal medicine as compared to conventional } \\
\hline Health care provider more accessible & 9.0 & I.I-74.I & 0.04 \\
\hline Herbalists are more accessible & 31.2 & $3.7-263.2$ & 0.002 \\
\hline They are equality accessible & Reference & & \\
\hline
\end{tabular}

Abbreviation: $\mathrm{Cl}$, confidence interval. 
Uganda amidst unpublished evidence of their safety and efficacy. Continuous public health awareness is suggested on the different natural remedies and further studies on the role of herbal medicine in patient management are recommended.

\section{Data Sharing Statement}

The data used to support the results of the research are available from the corresponding author upon request.

\section{Acknowledgments}

The authors would like to acknowledge administrative support from Mulago National Referral hospital, Namboole COVID-19 Treatment Unit, and Kiruddu Referral Hospital.

\section{Author Contributions}

All authors made substantial contributions to conception and design, acquisition of data, or analysis and interpretation of data, took part in drafting the article or revising it critically for important intellectual content, agreed to submit to the current journal, gave final approval to the version to be published, and agree to be accountable for all aspects of the work.

\section{Funding}

Research reported in this publication was supported by the Fogarty International Center of the National Institutes of Health, US Department of State's Office of the US Global AIDS Coordinator and Health Diplomacy (S/GAC), and President's Emergency Plan for AIDS Relief (PEPFAR) under Award Number 1R25TW011213. The content is solely the responsibility of the authors and does not necessarily represent the official views of the National Institutes of Health.

\section{Disclosure}

The authors declare no potential conflicts of interest for this work.

\section{References}

1. Alkhamaiseh SI, Aljofan M. Prevalence of use and reported side effects of herbal medicine among adults in Saudi Arabia. Complement Ther Med. 2020;48:102255.

2. Laelago T, Yohannes T, Lemango F. Prevalence of herbal medicine use and associated factors among pregnant women attending antenatal care at public health facilities in Hossana Town, Southern Ethiopia: facility based cross sectional study. Arch Public Health. 2016;74(1):1-8.
3. Rashrash M, Schommer JC, Brown LM. Prevalence and predictors of herbal medicine use among adults in the United States. J Patient Exp. 2017;4(3):108. pmc/articles/PMC5593261. doi:10.1177/ 2374373517706612

4. De Coninck J. Promoting herbal medicine in Uganda - ICH NGO Forum [Internet]. The status of traditional medicine; 2016 [cited September 14, 2021]. Available from: http://www.ichngoforum.org/ promoting-herbal-medicine-uganda/. Accessed November 5, 2021.

5. Aljofan M, Alkhamaiseh S. Prevalence and factors influencing use of herbal medicines during pregnancy in Hail, Saudi Arabia: a cross-sectional study. Sultan Qaboos Univ Med J. 2020;20(1):e716. doi:10.18295/squmj.2020.20.01.010

6. Nyeko R, Tumwesigye NM, Halage AA. Prevalence and factors associated with use of herbal medicines during pregnancy among women attending postnatal clinics in Gulu district, Northern Uganda. BMC Pregnancy Childbirth. 2016;16(1). pmc/articles/ PMC5053208. doi:10.1186/s12884-016-1095-5

7. Musoke P, Nantaayi B, Ndawula Kato R. Fear of COVID-19 and the media influence on herbal medication use in Uganda: a cross-sectional study. Risk Manag Healthc Policy. 2021;14:3965s75. doi:10.2147/RMHP.S332325

8. Ang L, Song E, Lee HW, Lee MS. Herbal medicine for the treatment of coronavirus disease 2019 (COVID-19): a systematic review and meta-analysis of randomized controlled trials. J Clin Med. 2020;9 (5): 1583.

9. Oreagba IA, Ogunleye OJ, Olayemi SO. The knowledge, perceptions and practice of pharmacovigilance amongst community pharmacists in Lagos state, south west Nigeria. Pharmacoepidemiol Drug Saf. 2011;20(1):30-35. doi:10.1002/pds.2021

10. Narcotic Drugs and Psychotropic Substances (control) Act. National Drug Policy and Authority Act (Chapter 206) | Ulii [Internet]. National Drug Policy and Authority Act; 2016 [cited September 14, 2021]. Available from: https://ulii.org/akn/ug/act/statute/1993/13/eng \%402016-02-15\#sec_5. Accessed November 5, 2021.

11. Quandt SA, Verhoef MJ, Arcury TA. Development of an international questionnaire to measure use of complementary and alternative medicine (I-CAM-Q). J Altern Complement Med. 2009;15(4):331-339. doi:10.1089/acm.2008.0521

12. Nguyen PH, De Tran V, Pham DT, Dao TNP, Dewey RS. Use of and attitudes towards herbal medicine during the COVID-19 pandemic: a cross-sectional study in Vietnam. Eur J Integr Med. 2021;44:101328. doi:10.1016/j.eujim.2021.101328

13. Abdullah Alotiby A, Naif Al-Harbi L. Prevalence of using herbs and natural products as a protective measure during the COVID-19 pandemic among the Saudi population: an online cross-sectional survey. Saudi Pharm J. 2021;29(5):410-417. doi:10.1016/j.jsps.2021.04.001

14. Auerbach BJ, Reynolds SJ, Lamorde M, et al. Traditional herbal medicine use associated with liver fibrosis in Rural Rakai, Uganda. PLoS One. 2012;7(11):e41737. doi:10.1371/journal.pone.0041737

15. Langlois-Klassen D, Kipp W, Rubaale T. Who's talking? Communication between health providers and HIV-infected adults related to herbal medicine for AIDS treatment in western Uganda. Soc Sci Med. 2008;67 (1):165-176. doi:10.1016/j.socscimed.2008.02.027

16. Lam CS, Koon HK, Chung VC-H, Cheung YT. A public survey of traditional, complementary and integrative medicine use during the COVID-19 outbreak in Hong Kong. PLoS One. 2021;16(7): e0253890. doi:10.1371/journal.pone.0253890

17. Kloos H, Mariam DH, Kaba M, Tadele G. Traditional medicine and HIV/AIDS in Ethiopia: herbal medicine and faith healing: a review. Ethiop J Health Dev. 2013;27(2):141-155.

18. Liwa AC, Smart LR, Frumkin A, Epstein HA, Fitzgerald DW, Peck RN. Traditional herbal medicine use among hypertensive patients in sub-Saharan Africa: a systematic review. Curr Hypertens Rep. 2014;16(6):437. 


\section{Publish your work in this journal}

Risk Management and Healthcare Policy is an international, peerreviewed, open access journal focusing on all aspects of public health, policy, and preventative measures to promote good health and improve morbidity and mortality in the population. The journal welcomes submitted papers covering original research, basic science, clinical \& epidemiological studies, reviews and evaluations, guidelines, expert opinion and commentary, case reports and extended reports. The manuscript management system is completely online and includes a very quick and fair peer-review system, which is all easy to use. Visit http://www.dovepress.com/testimonials.php to read real quotes from published authors.

Submit your manuscript here: https://www.dovepress.com/risk-management-and-healthcare-policy-journal 